chronic disease prevention. PPGs are block grants that require states to set up their own priorities in relation to Healthy People 2000 objectives, to allocate federal funds accordingly, and to be accountable for progress toward those objectives.

Proponents of block grants argue that categorical grants force local programs into "one-size-fits-all" national models, slow innovation, and encourage narrowly defined programs. In a recent editorial in The Nation's Health, the newspaper of the American Public Health Association, E. Richard Brown cautions that "state politics will determine the funding, and some important programs will end up as political orphans." Brown notes that "PPGs and other block grants will force public health agencies and community groups to fight each other for a share of the shrinking pie." The concern is that many states have weak public health and health policy infrastructures, limited economic resources, and strong political groups opposed to effective public health approaches.

If block grants are enacted, Brown proposes that they should require states to maintain current levels of funding and categorical set-asides for essential programs, services, and populations. Most importantly, the block grants should require states to develop performance objectives with participation by local communities and health departments.

FROM: Brown ER. Block grants and the public's health. The Nation's Health January 1996; p 40.

\section{FDA on Internet}

The latest press releases, enforcement reports, summaries of Federal Register notices, and other vital information from the US Food and Drug Administration (FDA) now are available on the World Wide Web at http://www.fda.gov. This Internet site offers more material, in a more user-friendly form, than the agency's electronic bulletin board, which had provided on-line information for more than a decade. The bulletin board was phased out at the end of 1995.

It is not necessary to subscribe to an Internet service provider to reach the FDA home page; the same free dialup connection that was used to connect to the FDA bulletin board can be used: 1-800-222-0185. For detailed information on making that connection, request the "FDA on the Internet" information sheet from the Office of Health Affairs, Mailing Code HFY-1, FDA, 5600 Fishers Ln, Rockville, MD 20857.

FROM: Nightingale S. From the Food and Drug Administration. JAMA 1995;274(24):1903.

\section{Managed Care and Public Health}

The CDC recently published a report on "Prevention and Managed Care: Opportunities for Managed Care Organizations, Purchasers of Health Care, and Public
Health Agencies." This report was developed by the Managed Care Working Group, formed by CDC in January 1995 to foster the incorporation of prevention into managed care. The report presents a summary of the systems for financing and delivering of health care in the United States, a review of the relationship between managed care and prevention, examples of the incorporation of prevention practices into managed care, and a list of the recommendations developed by the working group.

$\mathrm{CDC}$ has a key leadership role to play in fostering prevention in the private healthcare system. As one of the first steps in implementing the recommended activities of its Managed Care Working Group, CDC has designated a Managed Care Coordinator in the CDC Office of the Director. Those interested in more information about CDC's activities related to managed care and prevention may call the Managed Care Coordinator's office at (404) $639-4500$

FROM: Centers for Disease Control and Prevention. Prevention and managed care: opportunities for managed care organizations, purchasers of health care, and public health agencies. $M M W R$ 1005;44:(No. RR-14).

\section{Kentucky Guidelines on VRE}

Kentucky's Department of Health Service recently developed one of the first state guidelines to address prevention and management of vancomycin-resistant enterococci (VRE). These guidelines discuss clinical criteria for vancomycin use, responsibilities of the microbiology laboratory, and management of patients in the acute-care setting. They also address the issue of transfer of patients with VRE to nursing homes and prohibit the practice of requiring three negative cultures prior to transfer. The cited rationale is that the practice of restricting transfer until culture negative only "encourages more antibiotic use and does not differentiate between colonized and infected patients, and keeps patients who are ready for longterm-care settings in the acute-care setting unnecessarily.”

The guidelines were developed by a working group comprised of representatives from the Kentucky Department of Services and healthcare facilities in Kentucky. A copy of the "Guidelines for Prevention and Management of Vancomycin-Resistant Enterococci" may be obtained by writing to the Kentucky Department of Health Services, Division of Epidemiology, 275 E Main St, Frankfort, KY 40621, Attn: VRE Guidelines.

Additional news items in this issue: High Mortality for HIV Patients Following Cryptosporidiosis, page 164; TB Guideline Slides Available, page 182; Report on AntibioticResistant Bacteria, page 187; Conference on Reuse of Medical Devices, page 200. 